\title{
Income Inequality and Residential Carbon Emissions in the United States: A Preliminary Analysis ${ }^{\top}$
}

\author{
Andrew K. Jorgenson \\ Department of Sociology, \\ Boston College, Boston, United States \\ Juliet B. Schor \\ Department of Sociology, \\ Boston College, Boston, United States \\ Xiaorui Huang \\ Department of Sociology, \\ Boston College, Boston, United States \\ Jared Fitzgerald \\ Department of Sociology, \\ Boston College, Boston, United States
}

\section{Abstract}

The authors investigate the relationship between U.S. state-level residential carbon emissions and income inequality for the 1990-2012 period. Results of the analysis indicate a positive association between emissions and income inequality - measured as the Theil index - and these findings hold across a variety of model estimation techniques and net of the effects of other established human drivers of emissions. The authors conclude by underscoring the need for more research on the effects of income inequality on carbon emissions and other related environmental outcomes.

Keywords: climate change, income inequality, carbon emissions

\footnotetext{
1 The authors thank the anonymous reviewer and Thomas Dietz for helpful suggestions on a prior draft. Please direct all correspondence to Andrew Jorgenson, jorgenan@bc.edu.
} 


\section{Introduction}

Much research in the structural human ecology tradition focuses on the human drivers of greenhouse gas emissions. The majority of this research - to dateconsiders how population, affluence, and related factors explain growth in and variation between national-level emissions. Without doubt, population and affluence are primary drivers of national-level carbon emissions, methane emissions, and other greenhouse gases (e.g., Dietz, 2015; Dietz \& Jorgenson, 2013; Jorgenson \& Birkholz, 2010; Jorgenson \& Clark, 2012; Knight \& Schor, 2014; Rosa \& Dietz, 2012; Rosa, York, \& Dietz, 2004; Shandra et al., 2004; York, Rosa, \& Dietz, 2003).

Research that further broadens structural human ecology has considered how various forms of international inequality also shape uneven levels of and growth in national-level emissions and related outcomes. This research consistently shows that types of international inequalities tied to asymmetrical global production and trade networks as well as coercive forms of international power (e.g., military power) contribute to many environmental problems, including anthropogenic carbon emissions (e.g., Burns, Davis, \& Kick, 1997; Clark, Jorgenson, \& Kentor, 2010; Grimes \& Kentor, 2003; Jorgenson, 2012). Overall, these bodies of international research enhance our collective understanding of the human dimensions of global climate change and other environmental problems (Rosa et al., 2015).

With the growing availability of data, in recent years researchers have begun to investigate the human drivers of carbon emissions at smaller scales, such as at the U.S. state and county levels (e.g., Clement \& Schultz, 2011; Dietz et al., 2015; Elliott \& Clement, 2014). Many of the findings are consistent with the results of the comparative international research, especially the commonly observed impacts of population size, affluence, and urbanization. While it is recognized that comparative international research is important for a variety of substantive and practical reasons (Rosa et al., 2015), the assessment of society/ nature relationships at smaller scales allows for further theoretical testing as well as the execution of research with perhaps more actionable policy implications (Rudel, 2005), especially considering the gridlock in international negotiations on climate change (Ciplet, 2015; Roberts \& Parks, 2007).

A key issue that is absent from these streams of structural human ecology at all scales is research on greenhouse gas emissions and income inequality. Climate change and growth in income inequality are two of the most pressing problems of the current era. The former, if it continues unchecked, will not only undermine established ways of living, but also create catastrophic impacts on both natural and human systems (Intergovernmental Panel on Climate Change, 
2014). The latter not only increases poverty and undermines well-being, but has become so pronounced in some nations that it threatens their basic economic functioning (Piketty, 2014). If income inequality was found to contribute to environmental problems such as carbon emissions, and thus climate change, policies to reduce income inequality could be promoted as both ecologically and socially beneficial (Jorgenson, 2015).

This preliminary study seeks to help remedy this absence by assessing the relationship between carbon emissions and income inequality at the U.S. state level. ${ }^{2}$ In particular, we conduct a state-level longitudinal analysis of the effects of income inequality on residential carbon emissions for the 1990-2012 period. We employ the STIRPAT approach, a foundational tool in the structural human ecology tradition, in our analysis. The results suggest that income inequality, measured by the Theil index, increases residential carbon emissions in the United States, and these findings hold net of the effects of other well-established drivers of anthropogenic emissions.

\section{Brief literature review}

There are relatively few research findings on the relationship between carbon emissions and income inequality, and they mostly originate in the discipline of economics. We briefly summarize portions of this literature.

Ravallion et al. (2000) hypothesize that when the relationship between household income and emissions is concave, the wealthy emit less than the poor for each dollar of additional income, so that a redistribution of income from the wealthy to the poor will result in increased emissions. They posit that consumption demand is the key factor determining the increase of emissions induced by an increase in disposable income, i.e., the marginal propensity to emit. However, this is only one of the possible mechanisms at work. In a Keynesian model, lower-income households consume more than higher-income households for each dollar of additional income (i.e., the marginal propensity to consume declines with income). In that case, reductions in inequality that result in greater income for the poor yield a higher level of overall consumption demand and thus emissions.

In contrast, James Boyce's (1994, 2003, 2008) “power-weighted social decision rule" suggests that when the beneficiaries of environmental degradation are more powerful than those who bear the costs, the overall level of environmental degradation will be greater. Since the wealthy benefit more from environmental

2 While the focus for this preliminary study is on U.S. state-level emissions, in other research in progress we are investigating the relationship between carbon emissions and domestic inequality cross-nationally. 
degradation as both consumers and producers, and the poor benefit less and are more vulnerable to harmful consequences, higher levels of income inequality are likely to lead to increased carbon emissions and other environmental harms because the interests of the wealthy are protected in the political sphere (see also Cushing et al., 2015). In a similar vein, Pattison et al. (2014) find that counties in the U.S. with the highest average household incomes have greater consumptionbased carbon emissions but lower production-based emissions than less affluent counties. Pattison et al. (2014) conclude that wealthier communities are able to avoid some of the consequences of their carbon-intensive consumption by shifting carbon-intensive industrial activities into poorer areas.

Others have suggested that domestic inequality undermines environmental protection by reducing social cohesion and cooperation. By eroding social trust, income inequality may inhibit pro-environmental collective actions and socially responsible behaviors, thereby leading to growth in emissions (Cushing et al., 2015; Ostrom, 2008; Wilkinson \& Pickett, 2010). Related to this, Knight and Rosa (2011) demonstrate that countries with higher levels of social trust achieve greater subjective human well-being with less environmental impact.

Another approach argues that rising income inequality can increase statusbased consumption of goods and fossil fuels as individuals spend more and more to emulate the standards set by the "overconsuming" wealthier members of society in what we may call a Veblen effect (Schor, 1998; Veblen, 1934). Average working hours have also been shown to increase with rising income inequality (Bowles \& Park, 2005), and recent cross-national research indicates that longer working hours are associated with greater environmental impacts, including growth in energy consumption and carbon emissions (Fitzgerald, Jorgenson, \& Clark, 2015; Knight, Rosa, \& Schor, 2013).

Vona and Patriarca (2011) find that in wealthy countries, growth in income inequality reduces the development and diffusion of environmentally beneficial consumer products because it creates a larger gap between what wealthy early adopters are willing to pay and what the less wealthy can afford. And research by Jorgenson, Rice, and Clark (2010) shows that in developing nations, growth in fossil fuel consumption is positively associated with overall urbanization (the percent of the population residing in urban areas), but negatively associated with growth in urban slum prevalence (the percent of the population residing in urban slum conditions). Jorgenson et al. (2010) conclude that these divergent relationships are partly attributed to the differences in average incomes between urban slum residents and non-slum urban residents as well as the broader structural inequalities that inhibit access for urban slum residents to energy and other resources for household consumption. 
In this study, we explore a particular type of inequality - namely, high-income concentration at the top of the distribution. We hypothesize that where there is more income concentrated at the top, emissions will be higher for (at least) two reasons. First, there will be a stronger political economy effect in which the wealthy use their political power to avoid carbon-control measures. Second, high-income concentration leads to stronger Veblen effects in which highincome households compete for status via the "over-consumption" of goods and services which require high energy use (Schor, 1998; Ehrhardt-Martinez \& Schor, 2015). Veblen identified houses and transportation, both of which are highly energy intensive, as two of the three major areas of status competition (Veblen, 1934). High-income households today compete via the purchase of large homes (Dwyer, 2007; Frank, 2010), which in turn yields low population density and high residential energy use. In transportation, wealthy households purchase powerful motorized vehicles (autos, boats, and airplanes) and engage in frequent long-distance travel. In addition, this portion of the distribution engages in high consumption overall. More generally, this approach is in some ways similar to that of Chakravarty et al. (2009) who emphasize the strong intranational differences in carbon intensity, with emissions highly concentrated at the top of the income and wealth distribution.

\section{Data and methods}

\section{The dataset}

Our dataset contains annual observations from 1990 to 2012 for all 50 U.S. states, as well as the District of Columbia (i.e., 23 annual observations per case). This yields an overall sample of 1,173 observations, and a perfectly balanced panel dataset.

\section{Model estimation techniques}

We employ multiple model estimation techniques to assess the effect of income inequality on residential carbon emissions. Doing so allows for evaluating empirical relationships across a range of model specifications, each of which has its relative strengths and weaknesses (Allison, 2009). We first estimate random effects models, using the "xtreg" suite of commands in Stata version 13 software ("xtreg re"). ${ }^{3}$ One of the advantages of random effects models is the ability to include time invariant predictor variables (e.g., census region). We then estimate

\footnotetext{
3 We note that the Hausman test comparing the "xtreg" fixed effects model and random effects model is non-significant. Nonetheless, the estimated standard errors for the fixed effects model are generally larger than the random effects model, leading to more conservative hypothesis testing.
} 
fixed effects models, first with the within estimator in Stata ("xtreg fe"), and then with Prais-Winsten regression with panel corrected standard errors (xi:xtpcse). The fixed effects models and random effects models also include unreported year-specific intercepts.

All continuous variables are in logarithmic form (base 10), a well-established approach in structural human ecology, and commonly referred to as STIRPAT (Stochastic Impacts by Regression on Population, Affluence, and Technology; see stirpat.msu.edu/; York, Rosa, \& Dietz, 2003). Given that the variables are in logarithmic form, STIRPAT is by design an elasticity model. The coefficient for each continuous independent variable in such a model is the estimated percentage change in the dependent variable associated with a $1 \%$ increase in the independent variable, controlling for all other factors in the model.

\section{Dependent variable}

Our dependent variable is residential carbon dioxide emissions from fossil fuel combustion, measured in million metric tons $\mathrm{CO}_{2}\left(\mathrm{MMTCO}_{2}\right)$. We obtained these publicly available data from the United States Environmental Protection Agency (EPA), which provides state-level emissions data for various sectors, including residential, commercial, industrial, transportation, and electric power, as well as for all sectors combined (epa.gov/statelocalclimate/resources/ state_energyco2inv.html, accessed July 1, 2015). The EPA bases the state-level emissions estimates on energy consumption data from the EIA's State Energy Consumption, Price, and Expenditure Estimates (SEDS), released Spring 2014 (www.eia.doe.gov/emeu/states/seds.html).

\section{Independent variables}

Our measure of income inequality is the Theil index for household income inequality (Theil, 1967), which we obtain from Mark Frank's U.S. State-Level Income Inequality Database (www.shsu.edu/ eco_mwf/inequality.html, accessed July 3, 2015). The steps used in the creation of these inequality measures are provided in great detail in the Appendix in Frank (2014). The Theil index measures the discrepancies between the distribution of income and the distribution of population between groups. It compares the income and population distribution structures by summing across groups the weighted logarithm of the ratio between each group's income and population shares. When this ratio is one for a particular group, then that group's contribution to income inequality is zero (Conceicao \& Ferreira, 2000). An important property of the Theil index is its sensitivity to income transfers from the poor to the rich within a given population, which differentiates it from other common measures of income inequality, including the Gini coefficient. The Theil index tends to be 
highly correlated with more simple measures that quantify the percentage of all income or wealth owned by those in the top $1 \%$, top $5 \%$, and top $10 \%$, while the Gini coefficient tends to be only moderately correlated with such measures (Frank, 2014).

We include population size, measured in the number of persons, which we obtained from the United States Census Bureau database for state-level population estimates (www.census.gov/popest/data/intercensal/index.html, accessed July 1, 2015). We also include Gross Domestic Product (GDP) per capita by state, which we obtained from the United States Department of Commerce Bureau of Economic Analysis database (www.bea.gov/itable/, accessed July 1, 2015).

We note that there is a discontinuity in the time series of GDP by state at 1997, where annual estimates prior to that year are calculated using one classification system (and reported in chained 1997 dollars), while annual estimates from 1997 to the present (and reported in chained 2007 dollars) are calculated using a different classification system (for more information, see www.bea.gov/regional/ docs/product/). Thus, caution must be used when merging data from these two different panels into one overall dataset. We suggest that these differences are partially accounted for by the inclusion of year-specific fixed effects in all reported models, and we prefer to include these measures as a merged dataset to allow for greater temporal depth in our analysis of the residential emissions and income inequality relationship. In a sensitivity analysis available upon request, we restricted the overall dataset to 1997-2012, and the results of interest are substantively consistent with the findings reported below in Table 2 .

In the random effects models we also include dummy variables for Census Region, which consist of South Census Region (Alabama, Arkansas, District of Columbia, Florida, Georgia, Kentucky, Louisiana, Maryland, Mississippi, North Carolina, Oklahoma, South Carolina, Tennessee, Texas, Virginia, West Virginia), Midwest Census Region (Illinois, Indiana, Iowa, Kansas, Michigan, Minnesota, Missouri, Nebraska, North Dakota, Ohio, South Dakota, Wisconsin), Northeast Census Region (Connecticut, Delaware, Maine, Massachusetts, New Hampshire, New Jersey, New York, Pennsylvania, Rhode Island, Vermont), and West Census Region (Alaska, Arizona, California, Colorado, Hawaii, Idaho, Montana, Nevada, New Mexico, Oregon, Washington, Wyoming).

Table 1 provides the descriptive statistics and bivariate correlations for the dependent variable and the independent variables. As a reminder, all continuous variables are in logarithmic form (base 10). 
Table 1. Descriptive statistics and correlations

\begin{tabular}{|l|c|c|c|c|c|c|c|c|c|c|}
\hline & Mean & $\begin{array}{c}\text { Std. } \\
\text { Dev. }\end{array}$ & & $\mathbf{1 .}$ & $\mathbf{2 .}$ & $\mathbf{3 .}$ & $\mathbf{4 .}$ & $\mathbf{5 .}$ & $\mathbf{6 .}$ & $\mathbf{7 .}$ \\
\hline $\begin{array}{l}\text { Residential } \mathrm{CO}_{2} \\
\text { Emissions }\end{array}$ & 0.736 & 0.361 & $\mathbf{1 .}$ & & & & & & & \\
\hline Theil Index & 0.246 & 0.043 & 2. & 0.222 & & & & & & \\
\hline Population Size & 6.526 & 0.448 & 3. & 0.804 & 0.252 & & & & & \\
\hline GDP Per Capita & 4.549 & 0.135 & 4. & 0.023 & 0.587 & -0.074 & & & & \\
\hline South Census Region & 0.313 & 0.464 & 5. & -0.133 & -0.046 & 0.210 & -0.088 & & & \\
\hline Midwest Census Region & 0.235 & 0.424 & 6. & 0.258 & -0.193 & 0.061 & -0.063 & -0.375 & & \\
\hline $\begin{array}{l}\text { Northeast Census } \\
\text { Region }\end{array}$ & 0.196 & 0.397 & 7. & 0.198 & 0.203 & -0.082 & 0.141 & -0.333 & -0.273 & \\
\hline West Census Region & 0.254 & 0.436 & 8. & -0.291 & 0.052 & -0.207 & 0.026 & -0.395 & -0.324 & -0.288 \\
\hline
\end{tabular}

Notes:

- 1,173 total observations;

- all continuous variables are in base 10 logarithmic form;

- West Census Region is reference category in analysis reported in Table 2

\section{Results}

The findings for the analysis are provided in Table 2. RE Model 1 includes the Theil index, population size, GDP per capita, and the unreported period-specific intercepts. RE Model 2 also includes the measures for census region. The fixed effects models include the same predictors as the first random effects model. FE Model 1 is based on the "xtreg" within estimator, and FE Model 2 is based on Prais-Winsten regression with panel-corrected standard errors and unreported dummy variable case-specific fixed effects.

Across all four reported models, the effect of the Theil index on residential carbon emissions is positive and statistically significant. The elasticity coefficient for the Theil index is slightly larger in the fixed effects models (.143) than in the random effects models (.137 and .133), and in FE Model 2 the p-value for its coefficient is slightly above the standard benchmark of .05 with a value of .057 (two-tailed test). These results indicate that a $1 \%$ increase in the Theil index leads to between a $.133 \%$ and $.143 \%$ increase in residential carbon emissions, net of the effects of population size, level of economic development, and both the time-specific and state-specific fixed effects. 
Table 2. Longitudinal models of the effects of income inequality on residential $\mathrm{CO}_{2}$ emissions in all 50 U.S. states and Washington, DC, 1990-2012

\begin{tabular}{|l|c|c|c|c|}
\hline \multirow{2}{*}{ Theil Index } & RE Model 1 & RE Model 2 & FE Model 1 & FE Model 2 \\
\hline \multirow{2}{*}{ Population Size } & $0.137^{\star \star}$ & $0.133^{\star \star}$ & $0.143^{\star \star}$ & $0.143^{\star}$ \\
\cline { 2 - 5 } & $(0.058)$ & $(0.059)$ & $(0.059)$ & $(0.075)$ \\
\hline \multirow{2}{*}{ GDP Per Capita } & $0.792^{\star \star \star}$ & $0.780^{\star \star \star}$ & $0.835^{\star \star \star}$ & $0.835^{\star \star \star}$ \\
\cline { 2 - 5 } & $(0.032)$ & $(0.030)$ & $(0.037)$ & $(0.066)$ \\
\hline \multirow{2}{*}{ South Census Region } & $0.177^{\star \star \star}$ & $0.177^{\star \star \star}$ & $0.170^{\star \star \star}$ & $0.170^{\star \star \star}$ \\
\cline { 2 - 5 } & $(0.043)$ & $(0.043)$ & $(0.044)$ & $(0.059)$ \\
\hline \multirow{2}{*}{ Midwest Census Region } & & $-0.119^{\star \star}$ & & \\
\cline { 2 - 5 } & & $(0.058)$ & & \\
\cline { 2 - 5 } & & $0.191^{\star \star \star}$ & & \\
\hline Northeast Census Region & & $0.062)$ & & 0.995 \\
\cline { 2 - 5 } & & $(0.065)$ & & \\
\hline \multirow{2}{*}{ R-square } & 0.666 & 0.826 & 0.665 & \\
\hline
\end{tabular}

Notes:

- RE denotes random effects; FE denotes fixed effects;

- 1,173 total observations; ${ }^{\star} \mathrm{p}<.075,{ }^{* \star} \mathrm{p}<.05,{ }^{\star \star *} \mathrm{p}<.01$ (two-tailed tests); standard errors in parentheses;

- $\quad$-value for Theil Index coefficient is .057 in FE Model 2;

- all continuous variables are in base 10 logarithmic form; all models include unreported periodspecific intercepts;

- West Census Region is reference category in RE Model 2;

- FE Model 1 is estimated with the "xtreg" within estimator in Stata;

- $\quad F E$ Model 2 is estimated with Prais-Winsten regression with panel-corrected standard errors;

- FE Model 2 includes unreported dummy variable fixed effects for each case;

- Hausman test for FE Model 1 and RE Model 1 is nonsignificant.

As expected, the estimated effects of population size and GDP per capita are positive and statistically significant across the four models. In the second random effects model, all census region dummy variables exhibit statistically significant effects on emissions as well. We note that the close to perfect R-square statistic for FE Model 2 is largely due to the use of dummy variables for the case-specific fixed effects.

\section{Conclusion}

This study makes a modest contribution to structural human ecology research on the causes of anthropogenic greenhouse gas emissions, with a broader goal of bringing greater attention to and facilitating additional research on the environmental impacts of income inequality at multiple scales, a surprisingly 
understudied and overlooked topic. The results of our preliminary analysis suggest a positive relationship between state-level residential carbon emissions and income inequality, measured as the Theil index, in the United States, net of the effects of other well-established human drivers of emissions. For us, the next logical steps in this research involve evaluating the effects of other income inequality measures on state-level and national-level carbon emissions, such as the widely used Gini coefficient, which captures different properties of income distributions than the Theil index.

\section{References}

Allison, P. (2009). Fixed Effects Regression Models. Thousand Oaks, CA: Sage Publications.

Bowles, S., \& Yongjin, P. (2005). Emulation, inequality, and work hours: Was Thorsten Veblen right? The Economic Journal, 115(507), F397-F412.

Boyce, J. K. (1994). Inequality as a cause of environmental degradation. Ecological Economics, 11(3), 169-178.

Boyce, J. K. (2003). Inequality and environmental protection. Working Paper 52. Political Economy Research Institute, University of Massachusetts, Amherst.

Boyce, J. K. (2008). Is inequality bad for the environment? Research in Social Problems and Public Policy, 15, 267-288.

Burns, T., Davis, B., \& Kick, E. (1997). Position in the world-system and National Emissions of Greenhouse Gases. Journal of World-Systems Research, 3, 432-466.

Chakravarty, S., Chikkatur, A., de Coninck, H., Pacala, S., Socolow, R., \& Tavoni, M. (2009). Sharing global $\mathrm{CO}_{2}$ emission reductions among one billion high emitters. Proceedings of the National Academy of Sciences of the United States of America, 112, 11884-11888.

Ciplet, D. (2015). Rethinking cooperation: Inequality and consent in international climate change politics. Global Governance: A Review of Multilateralism and International Organizations, 21, 247-274.

Clark, B., Jorgenson, A. K., \& Kentor, J. (2010). Militarization and energy consumption: A test of treadmill of destruction theory in comparative perspective. International Journal of Sociology, 40, 23-43. 
Clement, M., \& Schultz, J. (2011). Political economy, ecological modernization, and energy use: A panel analysis of state-level energy use in the United States, 1960-1990. Sociological Forum, 26, 581-600.

Conceicao, P., \& Ferreira, P. (2000). The young person's guide to the Theil index: Suggesting intuitive interpretations and exploring analytical applications. UTIP Working Paper Number 14.

Cushing, L., Morello-Frosch, R., Wander, M., \& Pastor, M. (2015). The haves, the have-nots, and the health of everyone: The relationship between social inequality and environmental quality. Annual Review of Public Health, 36(1), 193-209.

Dietz, T. (2015). Prolegomenon to a structural human ecology of human wellbeing. Sociology of Development, 1, 123-148.

Dietz, T., Frank, K., Whitley, C., Kelly, J., \& Kelly, R. (2015). Political influences on greenhouse gas emissions from US states. Proceedings of the National Academy of Sciences, 112, 8254-8259.

Dietz, T., \& Jorgenson, A. K. (Eds.). (2013). Structural Human Ecology: New Essays in Risk, Energy, and Sustainability. Pullman, WA: Washington State University Press.

Dwyer, R. E. (2007). Expanding homes and increasing inequalities: US housing development and the residential segregation of the affluent. Social Problems, 54, 23-46.

Ehrhardt-Martinez, K., \& Schor, J. B. (2015). Consumption and climate change. In R. E. Dunlap and R. J. Brulle (Eds.), Climate Change and Society: Sociological Perspectives. New York: Oxford University Press.

Elliott, J., \& Clement, M. (2014). Urbanization and carbon emissions: A nationwide study of local countervailing effects in the United States. Social Science Quarterly, 95, 795-816.

Fitzgerald, J., Jorgenson, A. K., \& Clark, B. (2015). Energy consumption and working hours: A longitudinal study of developed and developing nations, 1990-2008. Environmental Sociology, 1, 213-223.

Frank, M. W. (2014). A new state-level panel of annual inequality measures over the period 1916-2005. Journal of Business Strategies, 31, 241-263.

Frank, R. H. (2010). Luxury Fever: Weighing the Cost of Excess. Princeton, NJ: Princeton University Press. 
Grimes, P., \& Kentor, J. (2003). Exporting the greenhouse: Foreign capital penetration and CO2 emissions 1980-1996. Journal of World-Systems Research, 9, 261-275.

Intergovernmental Panel on Climate Change. (2014). Climate Change 2014: Synthesis Report.

Jorgenson, A. K. (2012). The sociology of ecologically unequal exchange and carbon dioxide emissions, 1960-2005. Social Science Research, 41, 242-252.

Jorgenson, A. K. (2015). Inequality and the carbon intensity of human wellbeing. Journal of Environmental Studies and Sciences, 5, 277-282.

Jorgenson, A. K., \& Birkholz, R. (2010). Assessing the causes of anthropogenic methane emissions in comparative perspective, 1990-2005. Ecological Economics, 69, 2634-2643.

Jorgenson, A. K., \& Clark, B. (2012). Are the economy and the environment decoupling? A comparative international study, 1960-2005. American Journal of Sociology, 118, 1-44.

Jorgenson, A. K., Rice, J., \& Clark, B. (2010). Cities, slums, and energy consumption in less-developed countries, 1990-2005. Organization \& Environment, 23, 189-204.

Knight, K. W., \& Schor, J. B. (2014). Economic growth and climate change: A cross-national analysis of territorial and consumption-based carbon emissions in high-income countries. Sustainability, 6, 3722-3731.

Knight, K. W. \& Rosa, E. A. (2011). The environmental efficiency of well-being: A cross-national analysis. Social Science Research, 40, 931-949.

Knight, K. W., Rosa, E. A., \& Schor, J. B. (2013). Could working less reduce pressures on the environment? A cross-national panel analysis of OECD countries, 1970-2007. Global Environmental Change, 23(4), 691-700.

Ostrom, E. (2008). Frameworks and theories of environmental change. Global Environmental Change, 18(2), 249-252.

Pattison, A., Habans, R., \& Clement, M. T. (2014). Ecological modernization or aristocratic conservation? Exploring the impact of affluence on carbon emissions at the local level. Society \& Natural Resources, 27(8), 850-866.

Piketty, T. (2014). Capital in the Twenty-First Century. Cambridge, MA: Belknap Press.

Ravallion, M., Heil, M., \& Jalan, J. (2000). Carbon emissions and income inequality. Oxford Economic Papers, 52, 651-669. 
Roberts, T., \& Parks, B. (2007). A Climate of Injustice. Cambridge, MA: MIT Press.

Rosa, E. A., \& Dietz, T. (2012). Human drivers of national greenhouse-gas emissions. Nature Climate Change, 2, 581-586.

Rosa, E. A., Rudel, T., York, R., Jorgenson, A. K., \& Dietz, T. (2015). The human (anthropogenic) driving forces of global climate change. In R. E. Dunlap and R. J. Brulle (Eds.), Climate Change and Society: Sociological Perspectives. New York: Oxford University Press.

Rosa, E. A., York, R., \& Dietz, T. (2004). Tracking the anthropogenic drivers of ecological impacts. Ambio, 33(8), 509-512.

Rudel, T. (2005). Tropical Forests: Regional Paths of Destruction and Regeneration in the Late Twentieth Century. New York: Columbia University Press.

Schor, J. B. (1998). The Overspent American: Upscaling, Downshifting, and the New Consumer. New York: Basic Books.

Shandra, J., London, B., Wooley, O., \& Williamson, J. (2004). International nongovernmental organizations and carbon dioxide emissions in the developing world: A quantitative, cross-national analysis. Sociological Inquiry, 74, 520-44.

Theil, H. (1967). Economics and Information Theory. Chicago, IL: Rand McNally and Company.

United States Census Bureau. (2015). Database for state-level population estimates. Retrieved from www.census.gov/popest/data/intercensal/index.html.

United States Department of Commerce Bureau of Economic Analysis. (2015). Database for GDP per capita by state. Retrieved from www.bea.gov/itable/.

United States Energy Information Administration. (2014). Energy consumption data from the EIA's State Energy Consumption, Price, and Expenditure Estimates. Retrieved from www.eia.doe.gov/emeu/states/seds.html.

Veblen, T. (1934). Theory of the Leisure Class. New York: Modern Library.

Vona, F., \& Patriarca, F. (2011). Income inequality and the development of environmental technologies. Ecological Economics, 70(11), 2201-2213.

Wilkinson, R., \& Pickett, K. (2010). The Spirit Level: Why Equality is Better for Everyone. London: Penguin Books.

York, R., Rosa, E. A., \& Dietz, T. (2003). STIRPAT, IPAT and ImPACT: Analytic tools for unpacking the driving forces of environmental impact. Ecological Economics, 46, 351-365. 
This text is taken from Human Ecology Review, Volume 22, Number 1, 2015, published 2015 by ANU Press, The Australian National University, Canberra, Australia. 